\title{
Teachers' Attitudes Toward Teaching Integrated STEM: the Impact of Personal Background Characteristics and School Context
}

\author{
Lieve Thibaut $^{1}$ (D) Heidi Knipprath ${ }^{1}$. \\ Wim Dehaene ${ }^{2} \cdot$ Fien Depaepe $^{3}$
}

Received: 30 October 2017 / Accepted: 30 April 2018

(C) Ministry of Science and Technology, Taiwan 2018

\begin{abstract}
A promising approach to increase students' motivation for science, technology, engineering, and mathematics (STEM) is integrated STEM education (iSTEM). This is an instructional approach that emphasizes the deeper connections between the STEM disciplines by involving students in design challenges centered around realworld problems. However, the successful implementation of a new instructional approach, such as iSTEM, strongly depends on teachers' attitudes toward the innovation. Therefore, a deeper understanding of teachers' attitudes toward teaching iSTEM is necessary. This study uses a survey method to investigate the influence of teachers' background characteristics and school context variables on teachers' attitudes toward teaching iSTEM. To do so, a differential approach is used. Attitudes toward five key principles for iSTEM (integration, problem-centered, inquiry-based, design-based, and cooperative learning) are examined separately to get a more in-depth and nuanced insight into the factors influencing these attitudes. Results of the multiple regression analyses show that participation in professional development is positively linked to teachers' attitudes toward all key principles, whereas several other teacher and school context variables are positively correlated with attitudes toward one or two principles. Moreover, experience in mathematics and total years of teaching show a negative correlation with several aspects of teachers' attitudes toward teaching iSTEM. Findings
\end{abstract}

Lieve Thibaut

lieve.thibaut@kuleuven.be

1 Research Group Education and Labour Market, Research Institute for Work and Society (HIVA), KU Leuven, Parkstraat 47-Box 5300, 3000 Leuven, Belgium

2 MICAS, Microelectronics and sensors, Department of Electrical Engineering (ESAT), KU Leuven, Kasteelpark Arenberg 10-Box 2443, 3001 Leuven, Belgium

3 Centre for Instructional Psychology and Technology, Faculty of Psychology and Educational, Sciences, KU Leuven, Dekenstraat 2-Box 3773, 3000 Leuven, Belgium 
of this study are valuable, since they not only provide insight into possible barriers to the implementation of iSTEM but also suggest opportunities for overcoming these barriers.

Keywords Attitudes $\cdot$ Secondary education $\cdot$ STEM $\cdot$ Survey $\cdot$ Teachers

\section{Introduction}

Today's knowledge-based society thrives on scientific and technological innovations and requires people to continually learn new technologies (National Academies of Science, 2007). To provide all citizens with the competences required to succeed in this new information-based and highly technological society, education in the fields of science, technology, engineering, and mathematics (STEM) is becoming increasingly more important (National Society of Professional Engineers [NSPE], 2013). Nonetheless, particularly in highly developed countries, students often lack interest in STEM disciplines and are reluctant to participate in them (Schreiner \& Sjøberg, 2007).

A promising approach to improve both students' achievement in and motivation for STEM is the use of integrated STEM (iSTEM) education (Mustafa, Ismail, Tasir, Said, \& Haruzuan, 2016; Wang, Moore, Roehrig, \& Park, 2011). This is an instructional approach that aims at showing students the various ways in which the different STEM fields relate to each other by providing them with authentic, real-world engineering design challenges (Moore \& Smith, 2014; Wang et al., 2011). Prior research has shown that involving students in such an integrated curriculum can improve their interest and motivation for STEM (Mustafa et al., 2016; Wang et al. 2011).

Nonetheless, the implementation of a new instructional approach, such as iSTEM, is not straightforward and to optimally profit from its possible benefits, it is important that teachers are willing to implement iSTEM in alignment with its underlying principles (Durlak, 1998; Stains \& Vickrey, 2017). One factor that might be of specific interest in this regard is teachers' attitudes toward teaching iSTEM. Prior research (Thibaut, Knipprath, Dehaene, \& Depaepe, 2018b) has shown that teachers' attitudes are related to their classroom practices when teaching iSTEM and that teachers with negative attitudes toward STEM tend to avoid teaching it (Appleton, 2003). Therefore, a deeper understanding of these attitudes and the factors influencing them could help to advance the field and provide better recommendations for the implementation of iSTEM education.

However, existing research about factors related to teachers' attitudes toward teaching iSTEM is scarce. Several studies have adopted a qualitative approach to examine attitudes toward teaching iSTEM, using interviews and focus groups (e.g. Aldemir \& Kermani, 2017; Han, Yalvae, Capraro, \& Capraro, 2015). Although such qualitative methods are valuable for gaining an in-depth understanding of teachers' attitudes and their underlying reasons, findings cannot be generalized due to the small sample sizes. Other researchers have resorted to more quantitative methods, involving questionnaires to measure teachers' attitudes toward teaching iSTEM. Nonetheless, these questionnaires often use statements which include the term "integrated STEM" without explaining the specific instructional strategy underlying this term (e.g. Al 
Salami, Makela, \& de Miranda, 2017; Lin \& Williams, 2016) or only assess attitudes toward each of the different STEM disciplines individually, without taking the specific features of integration into account (e.g. Ho, Yang, \& Yang, 2016; Nadelson et al., 2013).

The current paper adds to existing research by employing a more detailed and finegrained method to examine teachers' attitudes toward iSTEM. Therefore, we used a questionnaire which focuses specifically on five defining features (or key principles) of iSTEM to measure attitudes. These key principles were derived through a systematic review of existing literature (Thibaut et al., 2018a) and are (1) integration of STEM content, (2) problem-centered learning, (3) inquiry-based learning, (4) design-based learning, and (5) cooperative learning. By examining teachers' attitudes toward each of these characteristics separately, a more detailed analysis of factors related to teachers' attitudes toward teaching iSTEM can be obtained. Moreover, although other researchers have examined factors related to teachers' attitudes toward teaching iSTEM, they mostly focus on the relationship between attitudes and professional development (e.g. Han et al., 2015; Nadelson et al., 2013). Nonetheless, other elements, such as individual and contextual characteristics, may also be correlated with teachers' attitudes (Clark et al., 2014). Therefore, the current study not only takes professional development into account but rather aims at investigating the influence of a broad range of teachers' background characteristics and school context variables on iSTEM teachers' attitudes toward each of the five iSTEM principles (integration, problem-centered, inquiry-based, design-based, and cooperative learning).

\section{Theoretical Background}

\section{Integrated STEM Education}

Integrated STEM education is an instructional approach in which students participate in engineering design and/or research and experience meaningful learning through integration and application of mathematics, technology, and/or science (Moore \& Smith, 2014). Through a systematic review of existing literature (a.o. Bryan, Moore, Johnson, \& Roehrig, 2015; Wang et al., 2011), a theoretical framework that articulates the essential components of the iSTEM approach was defined (Thibaut et al., 2018a). This framework consists of five STEM principles: integration of STEM content, problemcentered learning, inquiry-based learning, design-based learning, and cooperative learning.

The first principle, integration of STEM content, refers to the use of learning goals, content, and practices from different STEM disciplines (Bryan et al., 2015; Drake \& Burns, 2004). To achieve integration, learning objectives and learning activities from mathematics, science, and technology need to be aligned and connections between closely linked concepts in the different disciplines need to be made (Bryan et al., 2015).

Problem-centered learning, the second principle, indicates that learning environments should involve students in relevant and authentic problems to increase the meaningfulness of the content to be learned (Christensen, Knezek, \& Tyler-Wood, 2015). Therefore, ill-defined, real-world problems that allow for multiple solutions and 
refer to a problem in its totality, instead of only some components, should be used (Hmelo-Silver, 2004).

The third principle, inquiry-based learning, refers to learning environments that encourage questioning, thoughtful investigating, making sense of information, and developing new understandings (Diggs, 2009). Although this instructional approach originated from science education, where it usually entails that students have to plan and design experiments, collect data, and reflect on the results by providing explanations for scientific phenomena (Capps \& Crawford, 2013), inquiry-based learning is not restricted to this domain. It also occurs in mathematics, through questioning, challenging, discussing, interpreting, and exploring mathematical ideas (Menmuir \& Adams, 1997), and in technology, through using, discussing, and systematically assessing current and emerging technologies in an effort to understand them (Reed, 2003).

Another principle for iSTEM is design-based learning, in which students are encouraged to create some type of external artifact (e.g. a robot or a computer program), because learners are more inclined to construct new ideas when they are actively engaged in designing (Kafai \& Resnick, 1996). Important aspects of designbased learning include formulating hypotheses for possible solutions, planning and executing design, and reflecting on partial solutions in connection with the original problem (Ke, 2014).

Finally, the principle of cooperative learning indicates that students should get the opportunity to communicate and collaborate with each other to deepen their knowledge (Christensen et al., 2015). Crucial criteria for successful cooperative learning include positive interdependence between the group members, opportunities for face-to-face interaction, individual accountability of all group members, and time and space to reflect on the group process (Johnson \& Johnson, 1999).

To optimally profit from the possible benefits of iSTEM education, it is important that teachers implement it conform the underlying principles (Durlak, 1998; Stains \& Vickrey, 2017). According to the Social Cognitive Theory of Bandura (1986), future behavior - such as the selection of appropriate instructional methods for iSTEM-depends on three interrelated forces: environmental influences, a

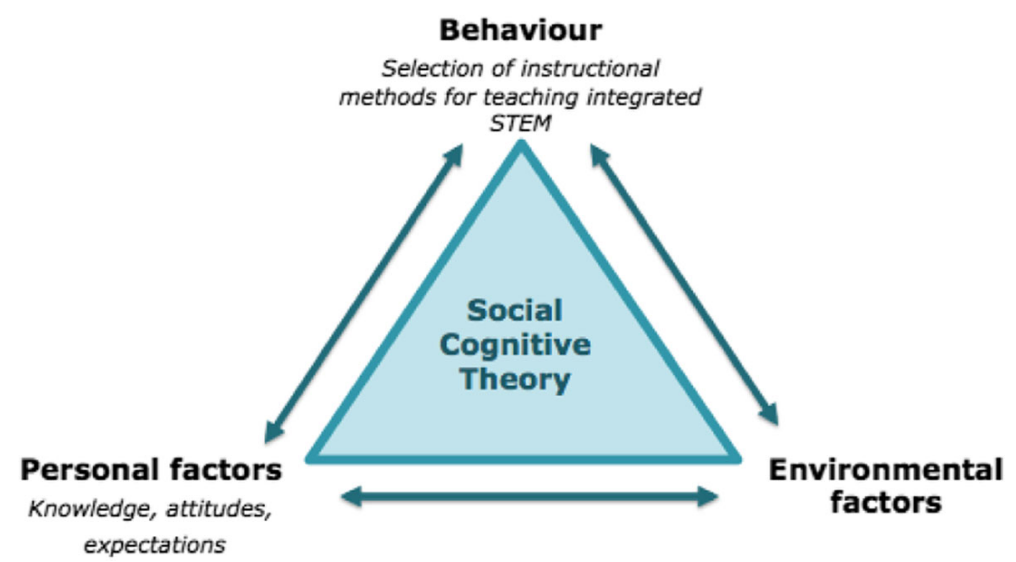

Fig. 1 Social cognitive theory by Bandura (1986) 
person's current and past behavior, and internal personal factors such as knowledge, attitudes, and expectations (Fig. 1) (Henson, 2001). In this study, the focus lies specifically on teachers' attitudes, because - as mentioned above-prior research has shown that teachers' attitudes are positively correlated with their classroom practices in iSTEM (Thibaut et al., 2018b).

\section{Teachers' Attitudes}

No general agreement about the definition of "attitudes" exists. Some researchers define attitudes as feelings toward an object or activity, i.e., an affective component, and distinguish them from beliefs, i.e., a cognitive component (Fishbein \& Ajzen, 1975; Koballa, 1988). By contrast, other researchers (Eagly \& Chaiken, 1993; van Aalderen-Smeets, Walma van der Molen, \& Asma, 2012) do not distinguish between both constructs and use the terms interchangeably. This paper uses the term "attitude" in this broad way, referring to the overall evaluation of an object or activity on several dimensions that can be affective or cognitive in nature (e.g. good/bad, pleasant/unpleasant) (Ajzen, 2005; Maio \& Haddock, 2014). According to Ajzen and Fishbein (2005), two types of attitudes exist: (1) general attitudes, which refer to broad, general objects, groups, or targets (e.g. iSTEM) and (2) attitudes toward behavior, which refer to the performance of specific behaviors with respect to an object or target (e.g. teaching iSTEM). Prior research has shown that general attitudes typically are poor predictors of specific behavior, whereas the same behavior can be predicted quite well from measures of attitude toward behavior (Ajzen \& Fishbein, 2005). Therefore, the current paper measures attitudes toward specific behavior (linked to the five key principles).

As mentioned above, attitudes refer to the overall evaluation of an object or activity on several dimensions. To define these dimensions, we relied on the work of van Aalderen-Smeets et al. (2012). They validated a framework for teachers' attitudes toward teaching science consisting of three dimensions: cognition, affect, and perceived control. Our framework, which is shown in Fig. 2, entails the same dimensions. However, unlike the framework of van Aalderen-Smeets et al. (2012), which measures teachers' attitudes on seven subscales divided over the three dimensions (Perceived Relevance, Perceived Difficulty, Gender Beliefs, Enjoyment, Anxiety, Self-Efficacy and Context Dependency), the current framework contains only one subscale for each dimension. This adaptation allows for a more detailed examination of the chosen subscales, while avoiding an abundance of questionnaire items.

Selection of the subscales from the original framework was guided by theoretical and methodological considerations. As mentioned above, in this study, attitudes are defined as one's personal evaluations of specific behavior. Therefore, in each dimension, the subscales best reflecting this focus on personal evaluations and specific

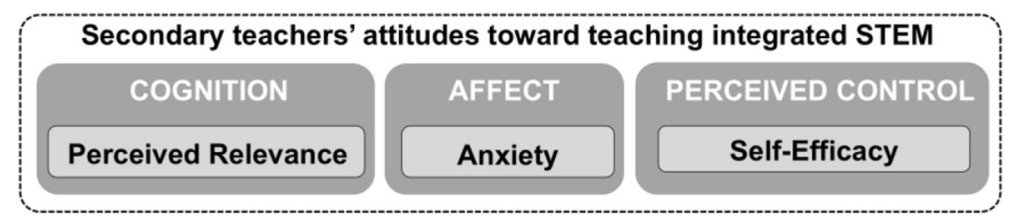

Fig. 2 Framework for teachers' attitudes toward teaching integrated STEM 
behavior were chosen. Since Gender Beliefs focus on differences in behavior between men and women, rather than on the specific behavior itself, and Perceived Difficulty refers to how difficult the community of teachers thinks a specific behavior is, rather than to a persons' own evaluation of difficulty, Perceived Relevance was chosen as subscale for the cognitive dimension. This subscale contains the opinions a teacher has about the relevance and importance of teaching iSTEM. For the dimension of perceived control, the subscale of Self-Efficacy (i.e. a person's conviction that he/she can successfully execute the behavior) was chosen in favor of Context Dependency (i.e. a persons' perceived dependence on context factors), because context factors are taken into account as a predictor variable in the current study. Finally, for the affective dimension, the subscale of Anxiety was chosen above Enjoyment, because prior research (Thibaut, Knipprath, Dehaene, \& Depaepe, 2017a) has shown that Enjoyment is strongly correlated with Self-Efficacy and therefore provides less additional value compared to Anxiety.

\section{Predictive Factors of Teachers' Attitudes}

Identifying factors that generate significant differences in teachers' attitudes is useful, since it allows for the formulation of recommendations to improve these attitudes and consequently the implementation of iSTEM education. As shown in Fig. 1, social cognitive theory points out one factor that has an influence on teachers' attitudes: environment. Nonetheless, other factors that underlie teachers' attitudes have been reported (Mellati, Khademi, \& Shirzadeh, 2015). Theoretical consensus across the literature on attitude formation suggests that attitudes are the consequence of an evolutionary process that involves all of an individual's experiences with the content (in this case, science, technology, engineering, and mathematics) throughout his entire life (Maasz \& Schlöglmann, 2009). Therefore, attitudes are strongly influenced by teachers' experiences both during the profession and as students (Richardson, 1996). The current investigation of predictive factors for teachers' attitudes toward teaching iSTEM takes both environmental factors (i.e. school context) and teachers' personal and professional experiences (i.e. background characteristics) into account.

\section{School Context}

According to the social cognitive theory (Bandura, 1986), teachers' attitudes can be influenced by the environment (Nespor, 1987). Various studies have empirically verified this relationship (e.g. Ayub, Bakar, \& Ismail, 2015; DeChenne, Koziol, Needham, \& Enochs, 2015). Nonetheless, no universally agreed-upon definition for school context exists (Cohen, McCabe, Michelli, \& Pickeral, 2009). Many researchers focus on promoting and measuring various aspects of schools and a variety of definitions and frameworks have been developed. Within the field of STEM education, the National Research Council (NRC) report (2011) has identified elements that are shared by schools that showed improvements in student learning in STEM. In this report, school leadership was named as the driver for change. Other influential aspects were the capacity of the staff to work together, the organization of the curriculum, and the tools teachers have to advance learning (such as instructional materials). 


\section{Background Characteristics}

Several background characteristics, including teachers' professional and personal experiences, could be important in the formation of teachers' attitudes.

Master (or Graduate) Degree Since instructional methods (e.g. the degree of students' active involvement) differ according to the educational level (e.g. Jarski, Kulig, \& Olson, 1990), a teacher's diploma can influence his or her attitudes. For example, prior research has shown that mathematics teachers with a graduate (or masters) degree have more positive attitudes toward teaching than teachers with undergraduate (or bachelor) education (Clark et al., 2014).

Years of Teaching Teachers who have been in the field longer have gained more professional experiences compared to novice teachers and would therefore exhibit different attitudes (Bandura, 1997). Researchers suggest that self-efficacy fluctuates over the course of a teaching career: teachers increase in self-efficacy through their early years and into the mid-career years but can decrease in efficacy as they enter the last stages of their careers (Klassen \& Chiu, 2010).

Experience in teaching science, technology, engineering, and/or mathematics Since teaching tasks and teaching situations are to a large extent shaped by the nature of the subject the teacher teaches (Chen \& Yeung, 2015), attitudes are influenced by teachers' domain-specific teaching experiences. Nonetheless, studies assessing subject-specific differences in teachers' attitudes toward interdisciplinary teaching are still elusive and rare. Al Salami et al. (2017) examined the change in attitudes to interdisciplinary teaching of 29 middle and high school teachers who participated in an interdisciplinary teaching and design problem unit that spanned multiple STEM subjects. At the start of the intervention, they reported less positive attitude scores for mathematics teachers compared to engineering/technology teachers and science teachers. Moreover, resistance to change was higher in mathematics teachers compared to the other group. However, over the course of the interdisciplinary unit, math teachers showed a decline in resistance to change and increasingly positive attitudes toward interdisciplinary teaching, while the opposite evolution was observed for science teachers. For engineering/technology teachers, no significant changes in attitudes were reported. Although further research is necessary, these results indicate that the effect of teaching iSTEM on teachers' attitudes differs among the different STEM disciplines.

Non-Teaching Work Experience Teachers with non-teaching work experience have had opportunities to encounter STEM content in an out-of-school context. Although we found no research about the influence of non-teaching work experience on teachers' attitudes toward STEM, studies in a broad range of fields have shown that occupational work experience increases teachers' confidence (Eck, 1969; Jones, 1973; King, 1986) and enables them to develop, apply, and integrate technical competencies into the classroom setting (King, 1986). 
Professional Development Opportunities to engage in professional development (PD) provide teachers with extra professional experiences and may therefore influence their attitudes and perceptions (Marzano, 2003). A number of studies have investigated this relationship and concluded that participation in quality PD influences teachers' attitudes toward teaching iSTEM (e.g. Aldemir \& Kermani, 2017; Nadelson et al., 2013).

Gender A final characteristic, which has been profoundly studied in regard to its possible influence on attitudes, is the gender of the teacher. Although it does not explicitly refer to an experience, male and female teachers are believed to have dissimilar personal and professional experiences, which could lead to different attitudes (Hackett \& Betz, 1981). However, studies regarding the influence of gender on teachers' attitudes proved conflicting. While some studies in the field of science and technology found that males report more positive attitudes than females (e.g. Denessen et al., 2011; Jones \& Levin, 1994), other researchers found no differences in teacher attitudes by gender at all (Metin, Acisli, \& Kolomuc, 2012).

\section{Purpose and Research Question}

The current study builds upon prior research on teachers' attitudes toward teaching iSTEM. Thibaut, Knipprath, Dehaene, and Depaepe (2017b) used a survey method with 135 teachers to get insight into the relationship between teacher background characteristics, school context variables, and teachers' attitudes toward teaching iSTEM. The results of the multiple regression analyses revealed that participation in professional development and social context were positively linked with teachers' attitudes. Moreover, two variables showed a negative correlation: having more than 20 years of teaching experience and experience in mathematics.

Although the findings of this study provided insight into possible barriers and opportunities for the successful implementation of iSTEM education, the research design had several limitations. The number of participants was relatively small $(n=135)$. Moreover, of the participants, only $51(37.8 \%)$ were actually involved in teaching iSTEM, whereas $84(62.2 \%)$ taught a core subject related to only one of the STEM domains. While it might be useful to understand the attitudes that the community of STEM teachers has toward teaching iSTEM, if the goal is to improve implementation, it is important to specifically examine the attitudes of teachers that actually use the new instructional approach. In addition, another limitation of the study by Thibaut et al. (2017b) was the measure used to investigate teachers' attitudes toward teaching iSTEM. Although the employed questionnaire was based upon the same five key principles as described in the theoretical framework, only one global measure was used to capture teachers' attitudes toward teaching iSTEM, which impedes the detailed analysis of these attitudes.

To overcome these limitations, the current study focuses specifically on a large sample $(n=263)$ of iSTEM teachers, instead of a mixture of iSTEM and 
STEM teachers. In addition, the study examines the relationship between background characteristics, school context, and teachers' attitudes separately for each of the defining features of iSTEM: integration of STEM content, problem-centered learning, inquiry-based learning, design-based learning, and cooperative learning. By examining teachers' attitudes toward each of these characteristics separately, a more detailed analysis of teachers' attitudes toward teaching iSTEM can be obtained. The specific research question of this study is: What is the influence of teachers' background characteristics and school context variables on their attitudes toward each of the five defining characteristics of iSTEM?

\section{Method}

\section{Sample and Procedure}

Data were gathered as part of a larger study about STEM education in Flanders. An online questionnaire was administered to 595 secondary (K6-K12) schools between January and March 2017. For this study, all teachers involved in teaching iSTEM were selected. This led to a sample of study consisting of 263 in-service teachers from 125 schools. The participants were approximately evenly divided in terms of gender $(47.2 \%$ female) with a mean age of 40 years (range 22-65 years) and an average teaching experience of 14.2 years (range 1-43 years). Other descriptive variables of the participants are given in Table 1.

\section{Measures of Attitudes Toward Teaching iSTEM}

To determine secondary teachers' attitudes toward teaching iSTEM, we developed a questionnaire in alignment with the theoretical framework. Items were created for each of the five distinguished STEM principles: integration of STEM content, problem-centered learning, inquiry-based learning, design-based learning, and cooperative learning. In line with the theoretical framework for teachers' attitudes of

Table 1 Descriptive statistics of the sample of participants

\begin{tabular}{llc}
\hline Variable & Description & Percent \\
\hline Female & Gender of the teacher & 47.2 \\
Master & Masters' degree obtained & 37.0 \\
Professional development & Participation in STEM-related professional development last year & 65.2 \\
Years of teaching & Total teaching experience of the teacher (in years) & 14.2 \\
Non-teaching work experience & Work experience in a non-teaching context & 48.9 \\
Experience in Science & Experience with teaching biology, physics, or chemistry & 87.9 \\
Experience in Engineering & Experience with teaching engineering & 31.0 \\
Experience in Math & Experience with teaching mathematics & 57.3 \\
Experience in Technology & Experience with teaching technology & 44.8 \\
\hline
\end{tabular}


van Aalderen-Smeets et al. (2012), items about teachers' perceived relevance, anxiety, and self-efficacy were developed. Next, a pilot study with 135 teachers was conducted (Thibaut et al., 2017b). Moreover, interviews with two pedagogical staff members, two physics teachers, one mathematics teacher, one chemistry teacher, and one engineering teacher were held. Based on the pilot study and the interviews, we adapted or removed several items in order to assure the construct validity of the questionnaire. Finally, 75 items were retained. Respondents were asked to indicate their level of agreement with these items on a five-point Likertscale $(1=$ totally disagree, $5=$ totally agree). All items about Perceived Relevance were formulated as "How important do you think it is to ...," items about SelfEfficacy as "How capable do you feel to do the following while teaching integrated STEM?" and items about Anxiety as "How anxious do you feel to do the following while teaching integrated STEM?" Sample items for all STEM principles are given in Table 2. Moreover, mean values and standard deviations for the three subscales (Perceived Relevance, Self-Efficacy, and Anxiety) in each of the STEM principles are given in this table.

To confirm construct validity of the questionnaire, confirmatory factor analysis (CFA) was performed. Conventional rules of thumb in CFA dictate that a sufficient model fit is achieved when the $\chi^{2} / d f$ value is lower than 2, CFI is higher than 0.90, and the RMSEA is at least lower than or equal to 0.08 (Marsh, Balla, \& Hau, 1996). In addition, the convergent validity, i.e., the degree of confidence we have that a latent construct is well measured by its observed indicators, was assessed by means of the average variance extracted (AVE) and composite reliability (CR). For AVE, values above 0.7 are considered very good, whereas the level of 0.5 is acceptable and the acceptable value of CR is 0.7 and above (Hair, Black, Babin, \& Anderson, 2010). Separate CFA models were constructed for each of the STEM principles. Model fit indices, AVE, and CR values for these CFA models are given in Table 2 and indicate that the questionnaire is a valid instrument for measuring secondary teachers' attitudes toward teaching iSTEM. Furthermore, to test the reliability of the questionnaire, the internal consistency was determined by computing the Cronbach's alpha coefficient for each subscale (Table 2). All Cronbach's alpha values exceed 0.7 , which is generally used as the threshold for an acceptable reliability coefficient (Nunnaly, 1978).

\section{Measures of Teacher Background, Knowledge, and School Context}

Teacher Background Adjoining the attitude questionnaire, survey items were included measuring personal background information including age, gender, experience in teaching (global and specific STEM courses), prior education, non-teaching work experience, and attendance of professional development. An overview of the investigated background factors is given in Table 1.

School Context Since no theoretical framework for school context within the field of iSTEM education exists, we used a combination of exploratory and confirmatory factor analysis to construct different school context factors. Based on the results of the NRC report (2011), 19 items referring to different elements of school environment were constructed. Teachers were asked to indicate to 


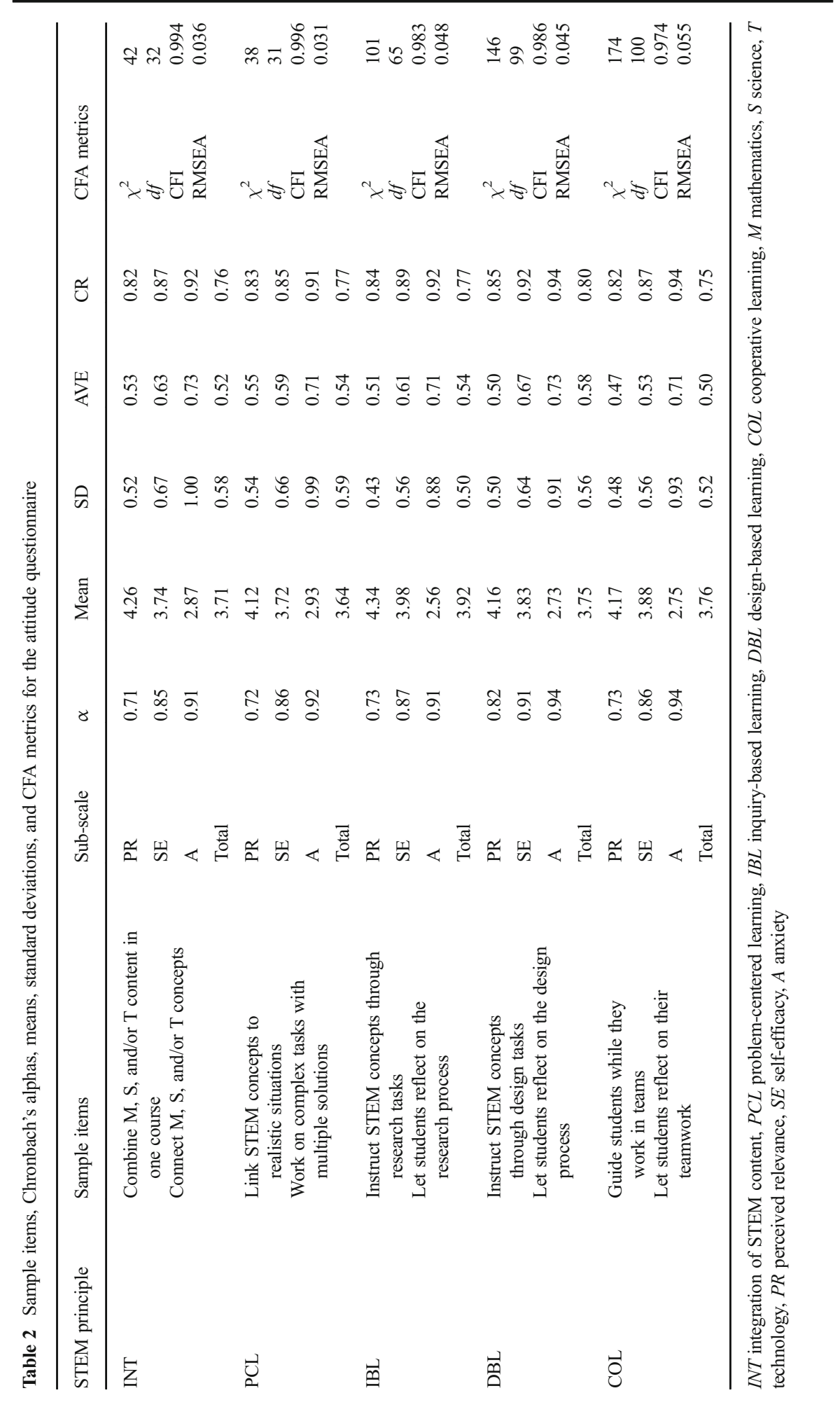


Table 3 Overview of the four categories of school context

\begin{tabular}{ll} 
Social context & Technical context \\
\hline - Multidisciplinary STEM team & - Functional classrooms \\
- Shared vision among colleagues & - Access to technical facilities \\
- Consultation meetings when necessary & - Technical material \\
- Consultation meetings at fixed times & - IT material \\
- "Free" time for preparation & - Budget \\
& - Technical support by experts \\
Management context & Organizational context \\
- Appreciation of management for STEM teachers & - Subsequent teaching hours \\
- Involvement of management in implementation & - Teaching hours for iSTEM \\
- Clear vision of management about STEM education & - Small-class groups \\
- Confidence of management in STEM teachers & - Co-teaching
\end{tabular}

which extent they felt the different elements were present in their school on a four-point Likert scale ( $1=$ totally absent, $4=$ more than adequately present). Exploratory factor analysis (EFA) with oblique rotation on half the dataset revealed four categories of school context: social, technical, management, and organizational context (Table 3 ). These categories roughly correspond with the factors named in the theoretical framework. Next, the other half of the dataset was used to validate the model through confirmatory factor analysis. Model fit indices $\left(\chi^{2}=222.46, d f=131, p=0.00, \mathrm{CFI}=0.96\right.$, RMSEA $\left.=0.054\right)$ show that the four-factor model is a good fit.

Data Analysis SPSS software (version 23.0) defined the predictor variables most suited to explain the variance in teachers' attitudes via five regression analyses, one for each STEM principle.

\section{Results}

Table 4 shows the standardized regression weights, $p$ values and explained variances of the five different regression analyses.

\section{Background Characteristics and Teachers' Attitudes}

The relationship between teachers' background characteristics and their attitudes differs depending on the STEM principle. While participation in professional development is strongly correlated with teachers' attitudes toward each STEM principle (range $b=$ 0.137 to 0.285 ), other background characteristics are only significantly correlated with attitudes toward one or two key principles. For example, gender (female) is only significantly correlated with attitudes toward cooperative learning $(b=0.212, p=$ $0.007)$ and having experience in teaching science only to attitudes toward integration $(b=0.181, p=0.005)$. Having experience in teaching technology is positively related to both attitudes toward integration $(b=0.262, p=0.001)$ and attitudes toward problemcentered learning $(b=0.158, p=0.040)$. In addition, one background characteristic is 


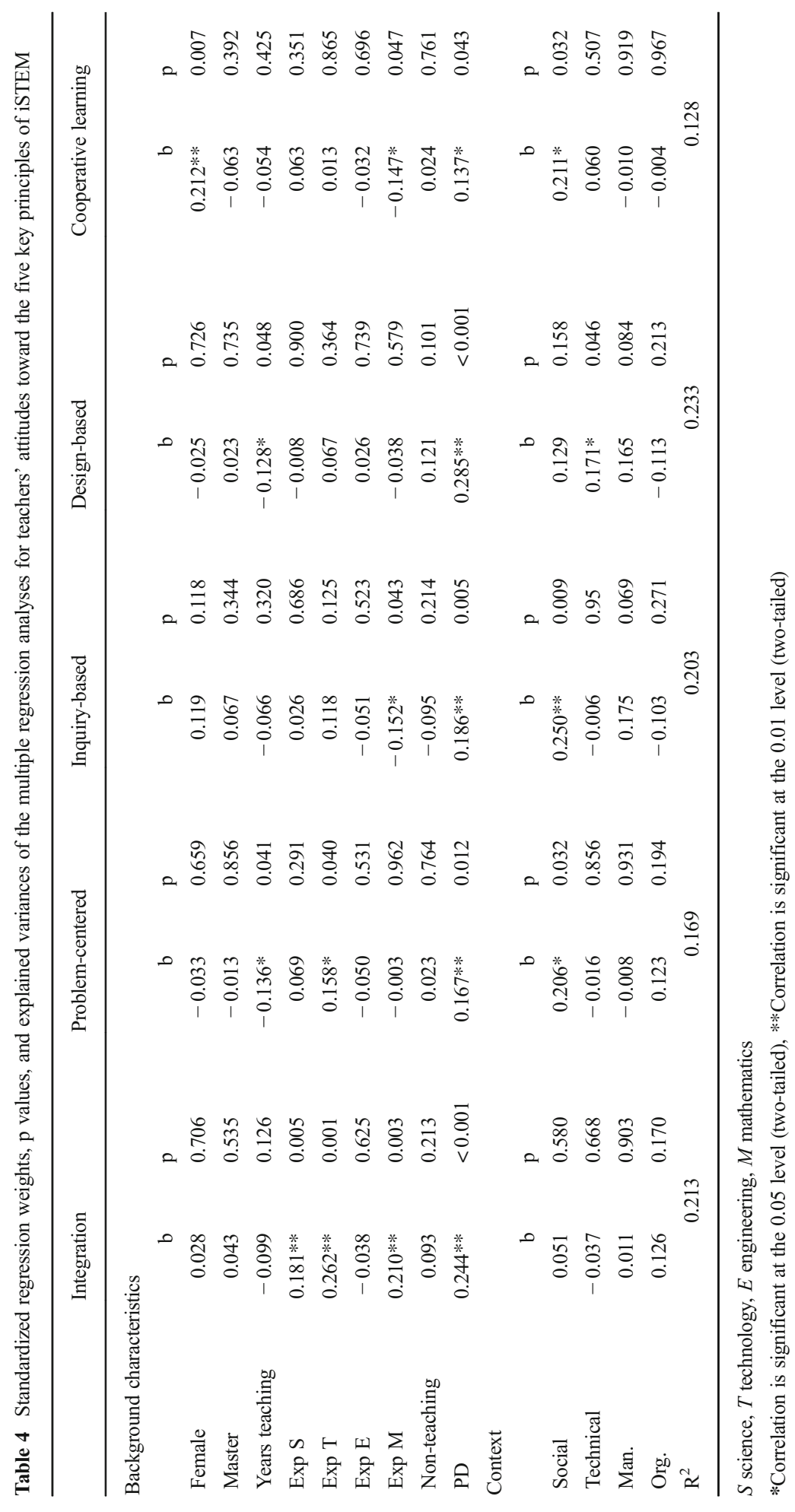


negatively correlated with teachers' attitudes toward teaching iSTEM: years of teaching. This variable shows negative correlations with attitudes toward both problemcentered learning $(b=-0.136, p=0.041)$ and design-based learning $(b=-0.128, p=$ 0.048). Moreover, a negative correlation between experience in teaching mathematics and teachers' attitudes toward both inquiry-based learning $(b=-0.152, p=0.043)$ and cooperative learning $(b=-0.147, p=0.047)$ was found. Nonetheless, this factor is positively correlated with attitudes toward integration of STEM content $(b=0.210, p=$ 0.003). For master diploma, experience in teaching engineering, and non-teaching work experience, no significant correlations with teachers' attitudes were found.

\section{School Context and Teachers' Attitudes}

Within the school context variables, social context has the strongest predictive value, since it is positively correlated with teachers' attitudes toward three of the key principles: problem-centered learning $(b=0.206, p=0.032)$, inquiry-based learning $(b=0.250, p=0.009)$, and cooperative learning $(b=0.211, p=0.032)$. In addition, technical context is significantly related to teachers' attitudes toward design-based learning ( $b=0.171, p=0.046)$. For management and organizational context, there are no significant correlations with teachers' attitudes toward teaching iSTEM.

\section{Discussion}

The main goal of this study was to find variables that can explain variation in teachers' attitudes toward teaching iSTEM. Since prior research has shown that teachers' attitudes are correlated with their instructional practices in iSTEM (Thibaut et al., $2018 \mathrm{~b}$ ), a deeper understanding of the factors related to these attitudes is useful to advance the field and provide better recommendations for the implementation of iSTEM. Teachers' attitudes are shaped by many factors, including both individual and contextual characteristics (Clark et al., 2014). Therefore, this study specifically examined the relationship between teachers' background characteristics, school context variables, and their attitudes toward teaching iSTEM.

To do so, we used a differential approach, based upon the five distinctive but related key principles for iSTEM education (integration of STEM content, problem-centered learning, inquiry-based learning, design-based learning, and cooperative learning). For each key principle, a separate multiple regression analysis was conducted to find significant correlations. By examining attitudes toward each key principle separately, rather than using an overall measure for attitudes toward teaching iSTEM, a more indepth and nuanced insight into the factors influencing these attitudes is provided.

\section{Main Findings}

Background Characteristics and Teachers' Attitudes Teachers' background characteristics were taken into account since they can influence the prevalence of different kinds of personal and professional experiences that can affect a person's attitude (Bandura, 1977). Results of the multiple regression analyses show that participation in professional development is positively correlated with teachers' attitudes toward all 
key principles of iSTEM. However, since we employed a cross-sectional rather than a longitudinal research design, these results do not necessarily indicate a causal relationship between professional development and teachers' attitudes. As mentioned above, according to social cognitive theory, attitudes and behavior are bi-directionally related (Bandura, 1986). This means that participation in professional development may lead to more positive attitudes toward teaching iSTEM or that teachers with more positive attitudes toward teaching iSTEM simply participate more often in professional development. Nonetheless, other researchers (e.g. Nadelson et al., 2013; Van AalderenSmeets \& Walma Van der Molen, 2015) who did use a longitudinal approach showed that professional development can be effective in changing teachers' attitudes.

In addition to participation in professional development, several other background characteristics are positively correlated to teachers' attitudes toward teaching iSTEM. However, the importance of these background characteristics differs depending on the STEM principle. For attitudes toward integration of STEM content, experience in science, technology, and mathematics all exert a positive correlation. This might indicate that having multi-disciplinary teaching experience is beneficial for attitudes toward integration. Nonetheless, further research which specifically compares the attitudes of teachers with multidisciplinary teaching experience to those of teachers who have only teaching experience in one subject is necessary to investigate this hypothesis. For problem-centered learning, a positive correlation between experience in teaching technology and attitudes exists. An explanation for this observation might be the specific nature of technology education. While science and mathematics aim at explaining and understanding natural processes, technology education is concerned with developing technological skills and knowledge of technological artifacts (Sade \& Coll, 2003). Since each technological artifact represents a designed solution, usually created in response to a specific practical problem, technology teachers are more accustomed to the problem-solving approach and might therefore exhibit more positive attitudes toward problemcentered learning, compared to their peers. For cooperative learning, a positive correlation between being female and attitudes exists. Although research about female teachers' attitudes toward cooperative learning is scarce or non-existing, prior research has shown that female students have a greater preference for group learning than their male peers (Felder, Felder, Mauney, Hamrin, \& Dietz, 1995) and are more enthusiastic in applying cooperative learning (Barham, 2002). It is plausible that this gender difference in attitudes, which is observed in students, is still present when those students become teachers.

Additionally, two background characteristics also show a negative correlation with several aspects of teachers' attitudes toward teaching iSTEM. The variable years of teaching is negatively correlated with teachers' attitudes toward problem-centered learning and design-based learning. Several researchers (e.g. Day \& Sachs, 2004; Huberman, 1989) have stated that teachers who approach the end of their careers have already experienced numerous educational changes and may therefore become resistant toward new changes. Since the implementation of problem-centered and design-based learning requires a substantial change in teachers' instructional practices, teachers with much teaching experience might be more reluctant toward these strategies.

Another factor that shows a negative correlation with several aspects of teachers' attitudes toward teaching iSTEM is experience in teaching mathematics. Although this 
factor is positively correlated with attitudes toward integration of STEM content, it is negatively correlated with attitudes toward inquiry-based learning and design-based learning. An explanation for this observation might be found in the specific nature of the subject. Mathematics teachers tend to see their subject more axiomatically oriented and less related to empirical findings than science teachers see their subject (Stodolsky \& Grossman, 1995). Moreover, math teachers use teamwork and experiments less frequently than science teachers (Engeln, Euler, \& Maass, 2013). Therefore, since mathematics teachers are less experienced in conducting experiments and guiding teamwork, they might exhibit lower levels of attitude toward inquiry-based learning and cooperative learning. In addition, Andersen and Krogh (2010) found that, depending on the subject, teachers have different conceptions of interdisciplinary teaching. Mathematics teachers exhibit a strong subject-oriented perspective on integration. They believe that interdisciplinary work should be grounded on traditional (mathematics) subject matter but with the addition of some extra perspectives. For example, mathematical topics - such as linear functions - could be enriched by adding technological applications - such as programming self-driving cars. However, in contrast to physics and biology teachers, none of the mathematics teachers questioned by Andersen and Krogh (2010) described interdisciplinary projects as an integration of subjects around real-life-issues, involving teamwork and design tasks. This specific subject-oriented perspective on integrated learning might explain why mathematics teachers display more negative attitudes toward inquiry-based and cooperative learning compared to their colleagues, while they are not necessarily more negative about integration of STEM content itself.

School Context and Teachers' Attitudes School context variables were taken into account in the multiple regression analyses, because social cognitive theory (Bandura, 1986) dictates the existence of a bi-directional relationship between environmental factors and a person's attitudes. Results of the current study reveal that social context is positively correlated with teachers' attitudes toward problem-centered learning, inquiry-based learning and cooperative learning. Prior research has confirmed the existence of this relationship. For example, Raudenbush, Rowan, \& Cheong, (1992) found that teachers who work in highly collaborative environments have elevated selfefficacy and Stohlmann, Moore, \& Roehrig, (2012) reported that weekly meetings to share ideas are beneficial for the implementation of an iSTEM program and help teachers to feel more comfortable. For integration of STEM content and design-based learning - the two STEM principles for which no significant correlation with social context was found - higher standardized regression weights for participation in professional development were found. This may indicate that for integration and design-based learning, teachers rely on their own knowledge and skills, rather than on support from and collaboration with their colleagues. However, we found no prior research comparing the relationship between school context and attitudes across the different STEM principles. Therefore, explanations for this observation remain hypothetical and further qualitative research (e.g. through interviews or focus groups with iSTEM teachers) is necessary to clarify the specific reasons behind this difference in correlation strength.

In addition, technical context was found to be positively correlated with teachers' attitudes toward design-based learning. Prior research has indeed shown the importance of technical resources for teachers' self-efficacy (e.g. DeChenne et al., 2015; 
Tschannen-Moran \& Woolfolk Hoy, 2002). However, these studies report a stronger connection between teachers' self-efficacy and the availability of resources, compared to the availability of collegial support. Findings from this study suggest that this is indeed the case for design-based learning, but not for the other key principles.

\section{Limitations and Perspectives for Further Research}

The results of the study are valuable since they address the lack of knowledge about factors influencing teachers' instructional practices in iSTEM. Nonetheless, the current research design has some limitations. One limitation is the fact that only questionnaires - or quantitative data — were used. Although this was a deliberate choice in order to examine the attitudes of a larger dataset, this approach also has some disadvantages. Respondents may provide socially desirable answers and are not given the opportunity to further explain their answers. Moreover, even when they are answering the questionnaire to the best of their ability, responses are subjective and may differ from reality. Therefore, future research could benefit from the addition of teacher interviews, classroom observations, or other qualitative data. That way, teachers' answers can be verified and more in-depth and detailed information about teachers' attitudes toward teaching iSTEM can be gathered. Another limitation of the study concerns the variables taken into account to explain the variance in teachers' attitudes toward teaching iSTEM. Although studies have demonstrated that background characteristics and school context are important factors influencing teachers' attitudes (e.g. Donaghue, 2003; Mellati et al., 2015), other factors have been found to affect these attitudes as well. For example, Clark et al. (2014) found that teachers' attitudes can also be influenced by teachers' knowledge and students' experiences. Since the explained variance in teachers' attitudes in this study is only moderate to low, the addition of other factors, such as teachers' knowledge or student experiences, could improve these values.

\section{Significance and Conclusion}

This research aimed at finding variables that can explain differences in secondary teachers' attitudes toward teaching iSTEM. To do so, five key principles for iSTEM were defined (i.e. integration of STEM content, problem-centered learning, inquirybased learning, design-based learning, and cooperative learning) and attitudes toward each of these key principles were examined by means of multiple regression analyses. Results show that participation in professional development is positively linked with teachers' attitudes toward all key principles, whereas several other variables are positively correlated with attitudes toward one or two key principles. Moreover, experience in mathematics and total years of teaching show a negative correlation with several aspects of teachers' attitudes toward teaching iSTEM.

Findings of this study are important, since they provide insight into the possible barriers for the successful implementation of integrated STEM education. Prior research by Thibaut et al. (2017b) already showed that both teachers with much teaching experience and teachers with experience in teaching mathematics exhibit less positive 
attitudes toward teaching iSTEM compared to their less-experienced colleagues from other disciplines. However, by examining the different key principles separately and by focusing specifically on iSTEM teachers, results of the current study further refine these earlier findings. Teachers with much teaching experience especially struggle with problem-centered learning and design-based learning. Moreover, mathematics teachers are not opposed to integration of STEM content itself; however, they do exhibit less positive attitudes toward inquiry-based learning and cooperative learning compared to their colleagues. Therefore, these results indicate that professional development targeted at improving (attitudes toward) specific key principles and adapted to a person's background experience could be more useful than generic professional development for improving teachers' attitudes and ultimately the implementation of iSTEM.

In addition, by using a differential approach to examine teachers' attitudes, the research results also suggest possibilities for improving specific aspects of teachers' attitudes toward teaching iSTEM. For example, adequate professional development is especially important to improve teachers' attitudes toward integration of STEM content and design-based learning, while opportunities for collaboration and consultation between different STEM teachers influence attitudes toward the other key principles. Moreover, access to technical resources is important, but only for improving teachers' attitudes toward design-based learning. These findings are valuable, as they allow school administrators to pinpoint specific shortcomings in their school's current implementation of iSTEM and explicitly target these aspects.

Funding This work was supported by the IWT-SBO (grant name STEM@school).

\section{Compliance with Ethical Standards}

Conflict of interest The authors declare that they have no conflict of interest.

\section{References}

Ajzen, I. (2005). Attitudes, personality, and behavior. London, England: McGraw-Hill Education.

Ajzen, I., \& Fishbein, M. (2005). The influence of attitudes on behavior. In D. Albarracín, B. T. Johnson, \& M. P. Zanna (Eds.), The handbook of attitudes (pp. 173-221). Mahwah, NJ: Lawrence Erlbaum Associates.

Al Salami, M. K., Makela, C. J., \& de Miranda, M. A. (2017). Assessing changes in teachers' attitudes toward interdisciplinary STEM teaching. International Journal of Technology and Design Education, 27(1), 6388. https://doi.org/10.1007/s10798-015-9341-0.

Aldemir, J., \& Kermani, H. (2017). Integrated STEM curriculum: Improving educational outcomes for head start children. Early Child Development and Care, 187(11), 1694-1706. https://doi.org/10.1080 /03004430.2016.1185102.

Andersen, H. M., \& Krogh, L. B. (2010). Science and mathematics teachers' core teaching conceptions and their implications for engaging in cross-curricular innovations. Nordic Studies in Science Education, 6(1), 61-79. https://doi.org/10.5617/nordina.270.

Appleton, K. (2003). How do beginning primary school teachers cope with science? Toward an understanding of science teaching practice. Journal for Research in Science Teaching, 33, 1-25. https://doi.org/10.1023 /A:1023666618800.

Ayub, A. F. M., Bakar, K. A., \& Ismail, R. (2015). Factors predicting teachers' attitudes towards the use of ICT in teaching and learning. In I. Mohamed, L. T. How, A. C. Y. Mui, \& W. K. Bin (Eds.), AIP Conference Proceedings (Vol. 1682, No. 1, p. 030010). Melville, NY: AIP Publishing.

Bandura, A. (1977). Self-efficacy: Toward a unifying theory of behavioral change. Psychological Review, 84(2), 191-215. https://doi.org/10.1037/0033-295X.84.2.191. 
Bandura, A. (1986). Social foundations of thought and action: A social cognitive theory. Englewood Cliffs, NJ: Prentice-Hall, Inc..

Bandura, A. (1997). Self-efficacy: The exercise of control. New York, NY: Freeman.

Barham, A. I. (2002). An assessment of the effectiveness of cooperative learning strategies in promoting problem-solving skills and achievement in mathematics (Doctoral dissertation). Retrieved from University of Huddersfield Repository: http://eprints.hud.ac.uk/id/eprint/6907/

Bryan, L. A., Moore, T. J., Johnson, C. C., \& Roehrig, G. H. (2015). Integrated STEM education. In C. C. Johnson, E. E. Peters-Burton, \& T. J. Moore (Eds.), STEM roadmap: A framework for integration (pp. 23-37). London, England: Taylor \& Francis.

Capps, D. K., \& Crawford, B. A. (2013). Inquiry-based instruction and teaching about nature of science: Are they happening? Journal of Science Teacher Education, 24(3), 497-526. https://doi.org/10.1007/s10972012-9314-z.

Chen, Z., \& Yeung, A. S. (2015). Self-efficacy in Teaching Chinese as a Foreign Language in Australian Schools. Australian Journal of Teacher Education, 40(8), 24 42. https://doi.org/10.14221/ajte.2015v40n8.2.

Christensen, R., Knezek, G., \& Tyler-Wood, T. (2015). Alignment of hands-on STEM engagement activities with positive STEM dispositions in secondary school students. Journal of Science Education and Technology, 24(6), 898-909. https://doi.org/10.1007/s10956-015-9572-6.

Clark, L. M., DePiper, J. N., Frank, T. J., Nishio, M., Campbell, P. F., Smith, T. M., Choi, Y. (2014). Teacher characteristics associated with mathematics Teachers' beliefs and awareness of their Students' mathematical dispositions. Journal for Research in Mathematics Education, 45(2), 246-284. https://doi. org/10.5951/jresematheduc.45.2.0246 .

Cohen, J., McCabe, L., Michelli, N. M., \& Pickeral, T. (2009). School climate: Research, policy, practice, and teacher education. Teachers College Record, 111(1), 180-213.

Day, C., \& Sachs, J. (2004). Professionalism, performativity and empowerment: Discourses in the politics, policies and purposes of continuing professional development. In C. Day \& J. Sachs (Eds.), International handbook on the continuing professional development of teachers (pp. 3-32). Maidenhead, England: Open University Press.

DeChenne, S. E., Koziol, N., Needham, M., \& Enochs, L. (2015). Modeling sources of teaching self-efficacy for science, technology, engineering, and mathematics graduate teaching assistants. CBE Life Sciences Education, 14(3), 1-14. https://doi.org/10.1187/cbe.14-09-0153.

Denessen, E., Vos, N., Damen, T., Koch, S., Louws, M., \& Wigboldus, D. (2011). Explicit and implicit measures of teacher attitudes towards science and technology. In M. J. de Vries, H. van Keulen, S. Peters, \& J. Walma van der Molen (Eds.), Professional development for primary teachers in science and technology (pp. 107-119). Dordrecht, The Netherlands: Sense Publishers.

Diggs, V. (2009). Ask-think-create: The process of inquiry. Knowledge Quest, 37(5), 30-33.

Donaghue, H. (2003). An instrument to elicit teachers' beliefs and assumptions. ELT Journal, 57(4), 344-351. https://doi.org/10.1093/elt/57.4.344.

Drake, S. M., \& Burns, R. C. (2004). Integrated curriculum, meeting standards through. Alexandria, VA: ASCD.

Durlak, J. (1998). Why program implementation is important. Journal of Prevention \& Intervention in the Community, 17(2), 5-18. https://doi.org/10.1300/J005v17n02_02.

Eagly, A. H., \& Chaiken, S. (1993). The psychology of attitudes. Fort worth, TX: Harcourt Brace Jovanovich College Publishers.

Eck, M. J. (1969). Occupational experience: A business teachers' asset. Business Education. Forum, 24(3), 30-31.

Engeln, K., Euler, M., \& Maass, K. (2013). Inquiry-based learning in mathematics and science: A comparative baseline study of teachers' beliefs and practices across 12 European countries. ZDM, 45(6), 823-836. https://doi.org/10.1007/s11858-013-0507-5.

Felder, R., Felder, G., Mauney, M., Hamrin, C., \& Dietz, J. (1995). A longitudinal study of engineering student performance and retention. III. Gender differences in student performance and attitudes. Journal of Engineering Education, 84(2), 151-163. https://doi.org/10.1002/j.2168-9830.1995.tb00162.x.

Fishbein, M., \& Ajzen, I. (1975). Belief, attitudes, intention, and behavior: An introduction to theory and research. Reading, MA: Addison-Wesley. Retrieved from https://www.GR\%20 downloadables/STEM\%20Education.pdf.

Hackett, G., \& Betz, N. E. (1981). A self-efficacy approach to the career development of women. Journal of Vocational Behavior, 18(3), 326-339. https://doi.org/10.1016/0001-8791(81)90019-1.

Hair, J., Black, W., Babin, B., \& Anderson, R. (2010). Multivariate data analysis. Upper Saddle River, NJ: Prentice-Hall. 
Han, S., Yalvae, B., Capraro, M. M., \& Capraro, R. M. (2015). In-service teachers' implementation and understanding of STEM project based learning. Eurasia Journal of Mathematics, Science \& Technology Education, 11(1), 63-76. https://doi.org/10.12973/eurasia.2015.1306a

Henson, R. K. (2001). Teacher self-efficacy: Substantive implications and measurement dilemmas. Invited keynote at the annual meeting of the Educational Research Exchange, Texas A \& M University, Texas.

Hmelo-Silver, C. E. (2004). Problem-based learning: What and how do students learn? Educational Psychology Review, 16(3), 236-262. https://doi.org/10.1023/B:EDPR.0000034022.16470.f3.

Ho, M. K., Yang, H. J., \& Yang, H. H. (2016). Design and Verify an instrument of assessing attitude toward STEM teaching. International Journal of Education and Information Technologies, 10, 41-50.

Huberman, M. (1989). The professional life cycle of teachers. Teachers College Record, 91(1), 31-57.

Jarski, R. W., Kulig, K., \& Olson, R. E. (1990). Clinical teaching in physical therapy: Student and teacher perceptions. Physical Therapy, 70(3), 173-178. https://oi.org/10.1093/ptj/70.3.173.

Johnson, D. W., \& Johnson, R. T. (1999). Making cooperative learning work. Theory Into Practice, 38(2), 6773. https://doi.org/10.1080/00405849909543834.

Jones, C., \& Levin, J. (1994). Primary/elementary teachers' attitudes toward science in four areas related to gender differences in students' science performance. Journal of Elementary Science Education, 6(1), 4666. https://doi.org/10.1007/BF03170649.

Jones Jr., M. E. (1973). Work experience programs in business education. Delta Pi Epsilon Journal, 15(2), $22-32$.

Kafai, Y. B., \& Resnick, M. (1996). Constructionism in practice: Designing, thinking, and learning in a digital world. Mahwah, NJ: Routledge.

Ke, F. (2014). An implementation of design-based learning through creating educational computer games: A case study on mathematics learning during design and computing. Computers \& Education, 73, 26-39. https://doi.org/10.1016/j.compedu.2013.12.010.

King, J. (1986). Keeping current: Eight teachers share their secrets. Vocational Education Journal, 61(5), 3638.

Klassen, R. M., \& Chiu, M. M. (2010). Effects on teachers' self-efficacy and job satisfaction: Teacher gender, years of experience, and job stress. Journal of Educational Psychology, 102(3), 741-756. https://doi. org/10.1037/a0019237.

Koballa, T. R. (1988). Attitude and related concepts in science education. Science Education, 72(2), 115-126. https://doi.org/10.1002/sce.3730720202.

Lin, K. Y., \& Williams, P. J. (2016). Taiwanese preservice teachers' science, technology, engineering, and mathematics teaching intention. International Journal of Science and Mathematics Education, 14(6), 1021-1036. https://doi.org/10.1007/s10763-015-9645-2.

Maasz, J., \& Schlöglmann, W. (Eds.). (2009). Beliefs and attitudes in mathematics education: New research results. Rotterdam, The Netherlands: Sense Publishers.

Maio, G., \& Haddock, G. (2014). The psychology of attitudes and attitude change. London, England: Sage Publications Ltd.

Marsh, H. W., Balla, J. R., \& Hau, K. T. (1996). An evaluation of incremental fit indices: A clarification of mathematical and empirical processes. In G. A. Marcoulides \& R. E. Schumacker (Eds.), Advanced structural equation modeling techniques (pp. 315-353). Hillsdale, MI: Erlbaum.

Marzano, R. J. (2003). What works in schools: Translating research into action. Alexandria, VA: ASCD.

Mellati, M., Khademi, M., \& Shirzadeh, A. (2015). The relationships among sources of teacher pedagogical beliefs, teaching experiences, and student outcomes. International Journal of Applied Linguistics and English Literature, 4(2), 177-184. https://doi.org/10.7575/aiac.ijalel.v.4n.2p.177.

Menmuir, J., \& Adams, K. (1997). Young children's inquiry learning in mathematics. Early Years, 17(2), 34 39. https://doi.org/10.1080/0957514970170207.

Metin, M., Acisli, S., \& Kolomuc, A. (2012). Attitude of elementary prospective teachers towards science teaching. Procedia-Social and Behavioral Sciences, 46, 2004-2008. https://doi.org/10.1016/j. sbspro.2012.05.418.

Moore, T. J., \& Smith, K. A. (2014). Advancing the state of the art of STEM integration. Journal of STEM Education: Innovations and Research, 15(1), 5-10.

Mustafa, N., Ismail, Z., Tasir, Z., Said, M., \& Haruzuan, M. N. (2016). A meta-analysis on effective strategies for integrated STEM education. Advanced Science Letters, 22(12), 4225-4228. https://doi.org/10.1166 /asl.2016.8111.

Nadelson, L. S., Callahan, J., Pyke, P., Hay, A., Dance, M., \& Pfiester, J. (2013). Teacher STEM perception and preparation: Inquiry-based STEM professional development for elementary teachers. The Journal of Educational Research, 106(2), 157-168. https://doi.org/10.1080/00220671.2012.667014

National Academies of Science. (2007). Rising above the gathering storm. Report from the committee on prospering in the global economy of the $21^{\text {st }}$ century. Washington, DC: National Academies Press. 
National Research Council. (2011). Successful K-12 STEM education: Identifying effective approaches in science, technology, engineering, and mathematics. Washington, DC: National Academies Press.

Nespor, J. (1987). The role of beliefs in the practice of teaching. Journal of Curriculum Studies, 19(4), 317328. https://doi.org/10.1080/0022027870190403.

National Society of Professional Engineers. (2013). Science, technology, engineering, and mathematics education. (NSPE Position Statement No. 1768). Retrieved from https://www.nspe. org/sites/default/files/resources/

Nunnaly, J. (1978). Psychometric theory. New York, NY: McGraw-Hill.

Raudenbush, S. W., Rowan, B., \& Cheong, Y. F. (1992). Contextual effects on the self-perceived efficacy of high school teachers. Sociology of Education, 65(2), 150-167. https://doi.org/10.2307/2112680.

Reed, P. A. (2003). Inquiry in technology education. In K. D. Helgeson \& A. E. Schwaller (Eds.), Selecting instructional strategies for technology education (pp. 117-129). Peoria, IL: Glencoe/McGraw-Hill.

Richardson, V. (1996). The role of attitudes and beliefs in learning to teach. In J. Sikula (Ed.), Handbook of research on teacher education (2nd ed., pp. 102-119). New York, NY: Macmillan.

Sade, D., \& Coll, R. (2003). Technology and technology education: Views of some Solomon Island primary teachers and curriculum development officers. International Journal of Science and Mathematics Education, 1(1), 87-114. https://doi.org/10.1023/A:1026155003835.

Schreiner, C., \& Sjøberg, S. (2007). Science education and youth's identity construction-Two incompatible projects? In D. Corrigan, J. Dillon, \& R. Gunstone (Eds.), The re-emergence of values in the science curriculum (pp. 231-249). Rotterdam, The Netherlands: Sense Publishers.

Stains, M., \& Vickrey, T. (2017). Fidelity of implementation: An overlooked yet critical construct to establish effectiveness of evidence-based instructional practices. Life Sciences Education, 16(1), 1-11. https://doi. org/10.1187/cbe.16-03-0113 .

Stodolsky, S. S., \& Grossman, P. L. (1995). The impact of subject matter on curricular activity: An analysis of five academic subjects. American Educational Research Journal, 32(2), 227-249. https://doi.org/10.3102 /00028312032002227.

Stohlmann, M., Moore, T. J., \& Roehrig, G. H. (2012). Considerations for teaching integrated STEM education. Journal of Pre-College Engineering Education Research (J-PEER), 2(1), 28-34. https://doi. org/10.5703/1288284314653

Tschannen-Moran, M., \& Woolfolk Hoy, A. (2002). The influence of resources and support on teachers' efficacy beliefs. Paper presented at the annual meeting of the American Educational Research Association, New Orleans, LA.

Thibaut, L., Knipprath, H., Dehaene, W., \& Depaepe, F. (2017a). Development and validation of an instrument for measuring teachers' attitudes toward teaching integrated STEM (HIVA Working Paper). Retrieved from Research Institute for Work and Society website: https://hiva.kuleuven. be/nl/backupoud/docs/working-papers/HIVA_WP2017_Lieve_Thibaut.pdf

Thibaut, L., Knipprath, H., Dehaene, W., \& Depaepe, F. (2017b). How school context and personal factors relate to teachers' attitudes toward teaching integrated STEM. International Journal of Technology and Design Education. Advance online publication. https://doi.org/10.1007/s10798-017-9416-1

Thibaut, L., Ceuppens, S., De Loof, H., De Meester, J., Goovaerts, L., Struyf, A., Depaepe, F. (2018a). Integrated STEM education: A systematic review of instructional practices in secondary education. European Journal of STEM Education, 3(1), 02. https://doi.org/10.20897/ejsteme/85525

Thibaut, L., Knipprath, H., Dehaene, W., \& Depaepe, F. (2018b). The influence of teachers' attitudes and school context on instructional practices in integrated STEM education. Teaching and Teacher Education, 71, 190-205. https://doi.org/10.1016/j.tate.2017.12.014

van Aalderen-Smeets, S. I., \& Walma van der Molen, J. H. (2015). Improving primary teachers' attitudes toward science by attitude-focused professional development. Journal of Research in Science Teaching, 52(5), 710-734. https://doi.org/10.1002/tea.21218.

van Aalderen-Smeets, S. I., Walma van der Molen, J. H., \& Asma, L. J. (2012). Primary teachers' attitudes toward science: A new theoretical framework. Science Education, 96(1), 158-182. https://doi.org/10.1002 /sce.20467.

Wang, H. H., Moore, T. J., Roehrig, G. H., \& Park, M. S. (2011). STEM integration: Teacher perceptions and practice. Journal of Pre-College Engineering Education Research, 1(2), 1-13. https://doi.org/10.5703 /1288284314636. 